\title{
A variant of SCID with specific immune responses and predominance of $\gamma \delta$ T cells
}

\author{
Stephan Ehl, ${ }^{1}$ Klaus Schwarz, ${ }^{2}$ Anselm Enders, ${ }^{1}$ Ulrich Duffner, ${ }^{1}$ Ulrich Pannicke, ${ }^{2}$ Joachim Kühr, ${ }^{3}$ \\ Françoise Mascart, ${ }^{4}$ Annette Schmitt-Graeff, ${ }^{5}$ Charlotte Niemeyer, ${ }^{1}$ and Paul Fisch ${ }^{5}$

\begin{abstract}
1Department of Pediatrics and Adolescent Medicine, University of Freiburg, Freiburg, Germany. ${ }^{2}$ Transfusion Medicine, University Hospital and Institute for Clinical Transfusion Medicine and Immunogenetics, UIm, Germany. ${ }^{3}$ Children's Hospital, Karlsruhe, Germany. ${ }^{4}$ Laboratory of Immunology, Hôpital Erasme, Université Libre de Bruxelles, Brussels, Belgium. Institute for Pathology, University of Freiburg, Freiburg, Germany.
\end{abstract}

\begin{abstract}
We describe here a patient with a clinical and molecular diagnosis of recombinase activating gene 1-deficient (RAG1-deficient) SCID, who produced specific antibodies despite minimal B cell numbers. Memory B cells were detected and antibodies were produced not only against some vaccines and infections, but also against autoantigens. The patient had severely reduced levels of oligoclonal T cells expressing the $\alpha \beta$ TCR but surprisingly normal numbers of T cells expressing the $\gamma \delta$ TCR. Analysis at a clonal level and TCR complementaritydetermining region-3 spectratyping for $\gamma \delta$ T cells revealed a diversified oligoclonal repertoire with predominance of cells expressing a $\gamma 4-\delta 3$ TCR. Several $\gamma \delta$ T cell clones displayed reactivity against CMV-infected cells. These observations are compatible with 2 non-mutually exclusive explanations for the $\gamma \delta \mathrm{T}$ cell predominance: a developmental advantage and infection-triggered, antigen-driven peripheral expansion. The patient carried the homozygous hypomorphic R561H RAG1 mutation leading to reduced V(D)J recombination but lacked all clinical features characteristic of Omenn syndrome. This report describes a new phenotype of RAG deficiency and shows that the ability to form specific antibodies does not exclude the diagnosis of SCID.
\end{abstract}

\section{Introduction}

SCID is the common phenotypic presentation of a range of genetic disorders (1). Depending on the gene affected, patients present with complete absence of $\mathrm{T}$ and $\mathrm{B}$ cells or, in most cases, with the absence of $\mathrm{T}$ cells (2). In a few SCID patients, however, $\mathrm{T}$ cells remain detectable in peripheral blood, rendering the clinical diagnosis more difficult. These $\mathrm{T}$ cells may be due to either materno-fetal transfusion (2) or hypomorphic mutations that allow residual function of the affected protein and thus partial $\mathrm{T}$ and $\mathrm{B}$ cell differentiation.

An example of SCID patients with partial T cell differentiation are patients with Omenn syndrome (OS) (3), the majority of which have hypomorphic mutations in recombinase activating gene 1 (RAG1) or RAG2 $(4,5)$. In contrast to patients with complete lossof-function mutations and complete lack of $T$ and $B$ cells, these patients retain partial $\mathrm{V}(\mathrm{D}) \mathrm{J}$ recombination activity and can generate a substantial number of oligoclonal $\mathrm{T}$ cells. However, they typically lack B cells, and despite the unexplained presence of high levels of IgE, no antigen-specific antibody responses can be detected. Another group of patients with missense mutations in the $R A G 1$ or RAG2 genes does not show the typical clinical features of OS, including generalized eczema, lymphadenopathy, and hepatosplenomegaly (5). Also, these patients, designated as atypical SCID/OS patients, do not generate specific immune responses. Thus, despite the substantial phenotypic diversity among patients with RAG deficiency, the common immunological feature is the absence of antigen-specific immunity, which is the basis for the

Nonstandard abbreviations used: CDR3, complementarity-determining region-3; HFF, human foreskin fibroblast; OS, Omenn syndrome; PHA, phytohemagglutinin; RAG1; recombinase activating gene 1 .

Conflict of interest: The authors have declared that no conflict of interest exists.

Citation for this article: J. Clin. Invest. 115:3140-3148 (2005).

doi:10.1172/JCI25221. extreme susceptibility to infection and a key parameter for the clinical diagnosis of SCID.

Here we report a new SCID phenotype in a patient with a hypomorphic mutation in RAG1 that is clearly distinct from $\mathrm{T}^{-} \mathrm{B}^{-} \mathrm{SCID}$ (SCID characterized by an absence of both $\mathrm{T}$ and $\mathrm{B}$ lymphocytes) and OS. It includes normal immunoglobulin levels, specific antibody responses to some infectious agents and vaccine antigens, the production of autoantibodies, a predominance of $\gamma \delta \mathrm{T}$ cells, and the development of EBV-associated lymphoproliferation.

\section{Results}

Case report. The patient is the second daughter of consanguinous Turkish parents. She presented first at the age of 4 months with prolonged varicella. The mother had developed varicella at the same time, and the protracted course in the child was ascribed to the lack of attenuating maternal antibodies. At the age of 7 months, the child was hospitalized with perforated otitis media, bronchopneumonia, and genital candida infection. There was initial improvement after intravenous antibiotic treatment, but over the next 3 months, there were 3 further hospitalizations for pneumonia and persistent oral and genital candida infections. At 10 months of age, the patient developed respiratory failure requiring intubation. Fluid from a bronchoalveolar lavage was positive for CMV. Coombs-positive anemia was detected as was severe neutropenia with predominance of myelocytes and lack of more mature granulocytic precursors in the bone marrow. There was lymphopenia with almost complete absence of $\mathrm{CD} 4^{+} \mathrm{T}$ cells, few $\mathrm{CD} 8^{+} \mathrm{T}$ cells, severely reduced numbers of $\mathrm{B}$ cells, and normal levels of NK cells (Table $1)$. The thymus was markedly reduced in size. However, there were normal to elevated levels of serum immunoglobulins. The patient was transferred to our service for further management.

The girl stabilized following ganciclovir treatment, but subsequently developed patchy, ovaloid infiltrates in the lung (Figure 1A) and facial paralysis due to a sterile mastoiditis. Biopsies from 


\section{Table 1}

Comparison of the clinical and immunological phenotypes of 3 patients with homozygous $\mathrm{R} 561 \mathrm{H}$ RAG1 mutations

\begin{tabular}{|c|c|c|c|c|}
\hline Patient & P1 & OS2 & P27 & Normal range \\
\hline Mutation & $\mathrm{R} 561 \mathrm{H} / \mathrm{R} 561 \mathrm{H}$ & R561H/R561H & $\mathrm{R} 561 \mathrm{H} / \mathrm{R} 561 \mathrm{H}$ & \\
\hline Age at analysis & 11-13 mo & $2 \mathrm{mo}$ & $11 \mathrm{mo}$ & $9-15 \mathrm{mo}$ \\
\hline Clinical history & $\begin{array}{c}\text { CMV, VZV, EBV } \\
\text { Iymphoproliferation }\end{array}$ & $\begin{array}{l}\text { Staphylococcal } \\
\text { sepsis }\end{array}$ & $\begin{array}{c}\text { Dermatitis, pharyngeal } \\
+ \text { vulval ulcer }\end{array}$ & \\
\hline Erythroderma & - & + & - & - \\
\hline Lymphadenopathy & - & + & - & - \\
\hline Hepato/splenomegaly & - & + & - & - \\
\hline Eosinophils/ul & 420 & 4,550 & 0 & \\
\hline Lymphocytes/ul & $400-830$ & 720 & $400-612$ & $2600-10,400$ \\
\hline $\mathrm{CD}^{+}{ }^{+}$cells $/ \mu \mathrm{l}$ & $200-350$ & 245 & $105-135$ & $1,600-6,700$ \\
\hline $\mathrm{CD} 3^{+} \mathrm{CD}^{+}{ }^{+}$cells/ul & $1-25$ & 78 & & $1,000-4,600$ \\
\hline CD3+CD8+ cells/ul & $50-76$ & 59 & & $400-2,100$ \\
\hline CD19+ cells/ul & $12-24$ & 14 & $0-10$ & $600-2,700$ \\
\hline CD3-CD16+56+ cells/ul & $164-178$ & 312 & $120-280$ & $200-1,200$ \\
\hline TCR $\gamma \delta^{+}$cells $\left(\%\right.$ of $\left.\mathrm{CD}^{+}\right)$ & 66 & 6 & n.d. & $<10$ \\
\hline PHA response (cpm) & $21,661(>40,000)$ & $5,700(>55,000)$ & $58,297(410,479)^{A}$ & \\
\hline Anti-CD3 response (cpm) & ) $16,960(>34,000)$ & $2,460(>50,000)$ & n.d. & \\
\hline $\lg G(g / l)$ & 16.7 & 2.9 & 3.5 & $3.8-12.5$ \\
\hline $\lg M(g / l)$ & 2.6 & 0.09 & 0.18 & $0.2-0.9$ \\
\hline $\lg A(g / l)$ & 1.4 & $<0.06$ & 0.19 & $0.1-0.7$ \\
\hline $\lg \mathrm{E}(\mathrm{U} / \mathrm{ml})$ & 20 & 190 & n.d. & $<50$ \\
\hline Specific Ab & + & - & n.d. & + \\
\hline Autoantibodies & + & n.r. & + & - \\
\hline Neutropenia & + & n.r. & + & - \\
\hline
\end{tabular}

The main characteristic features of the individual phenotypes are indicated in bold. The presented patient is designated P1. The data on patient OS2 $(4,31,32)$ and in part on patient P27 (6) were published previously. ${ }^{\mathrm{A} L o c a l}$ healthy control. n.d., not done; n.r., not reported; VZV, varicella-zoster virus.

$\mathrm{G} \rightarrow$ A substitution at nucleotide 1806 of the RAG1 gene (reference sequence NM_000448) was found, leading to a R561H exchange. Both parents were heterozygous for this RAG1 mutation. The same homozygous mutations have been previously reported in 2 patients with RAG1 deficiency $(4,6)$. Table 1 summarizes the main clinical and immunological features of the 3 patients, illustrating the phenotypic variability of RAG1 deficiency.

Phenotype and function of the $B$ cell compartment. To rule out the presence of maternal lymphocytes, short terminal repeat analysis was performed on sorted $\mathrm{CD}^{+}$and $\mathrm{CD} 19^{+}$cells $(95 \%$ purity). The few detectable $B$ and $\mathrm{T}$ cells (Table 1 ) were of patient origin (data not shown). Immunoglobulins of all major classes, including all $4 \mathrm{IgG}$ subclasses, were present at normal to elevated levels (Table 1). Moreover, several specific antibodies could be demonstrated. Vaccine titers to diphtheria, but not to tetanus, were present after 3 vaccinations. High titers of IgG to vari-

both lesions showed dense polymorphic lymphoproliferation with areas of necrosis and pseudocystic degeneration. Medium- to large-sized CD20+ lymphoid cells (Figure 1B) with scattered CD15CD30+ Reed-Sternberg-like cells expressed the EBV-encoded latent membrane protein (LMP) (Figure 1C). The same rearrangement was found in both lesions, demonstrating monoclonality (Figure 1D). An EBV PCR in peripheral blood revealed 22,000 copies $/ \mathrm{ml}$. Therapy with anti-CD20 mAb was initiated, which rapidly controlled EBV load and led to a significant decrease in pulmonary lymphoproliferation. The patient was placed on a preparative myeloablative regimen before receiving a bone marrow transplant from an EBV-positive, unrelated donor with a single mismatch at the $\mathrm{C}$ locus. Not unexpectedly, there was rapid expansion of donor $\mathrm{CD}^{+}$ $\mathrm{T}$ cells, with subsequent complete elimination of the lymphoproliferative lesions. Six months after transplantation, the patient was at home, with normal lymphocyte counts and proliferative responses and an increasing proportion of naive $T$ cells, indicating thymic regeneration.

Genetic analysis. Because of the low B cell count, genetic analysis focused on genes involved in $\mathrm{V}(\mathrm{D}) \mathrm{J}$ recombination. A homozygous

\section{Figure 1}

Multifocal monoclonal EBV-induced lymphoproliferation. (A) CT scan of the lung demonstrating large ovaloid lesions. (B and $\mathbf{C}$ ) Polymorphic lymphoproliferation of the lung consisting of $\mathrm{CD} 2 \mathrm{O}^{+} \mathrm{B}$ cells that coexpressed EBV LMP-1. (D) Clonality analysis of lymphoproliferative lesions. $\operatorname{lgH}$ gene scan profiles from lung and mastoid biopsy DNA are shown. cella were detectable. Since the mother developed primary varicella at the same time as the patient, these were unlikely to be maternal antibodies. Furthermore, IgM and IgG to CMV were detectable (Table 1). CMV infection was well documented by clinical signs and PCR studies, excluding nonspecific responses induced by polyclonal B cell activation. The patient also developed a positive direct Coombs test, with high titers of anti-erythrocyte antibodies, and experienced severe neutropenia, which responded to the

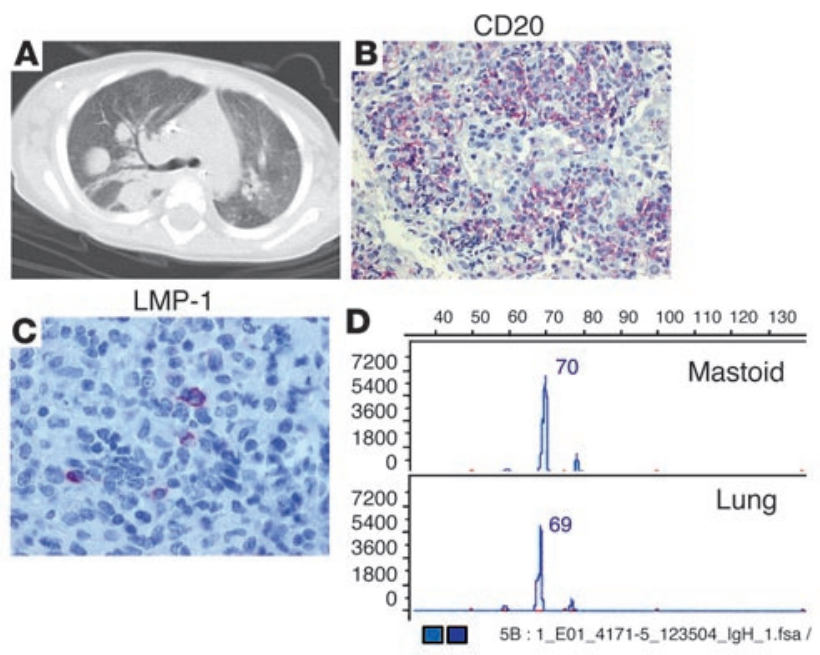


A

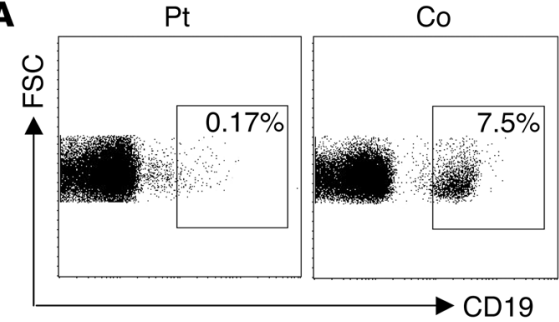

B

\section{Figure 2}

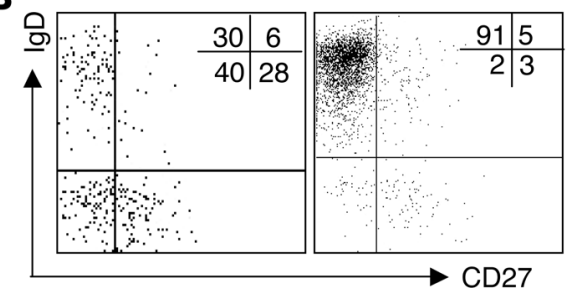

B cell phenotype. (A) Proportion of CD19+ B cells in the patient (Pt) and an age-matched control (Co) patient without immunological abnormalities. (B) Expression of IgD and the memory marker CD27 on $C D 19+B$ cells.

EBV-directed therapy with anti-CD20 antibodies. Consistent with specific antibody production, $\mathrm{B}$ cells expressing the memory marker $\mathrm{CD} 27$ could be detected among both $\operatorname{IgM}^{+} \mathrm{B}$ cells and IgMswitched memory B cells (Figure 2). These findings of functional specific B cell immunity induced by vaccination, infection, and autoantigens were in obvious contrast to the SCID indicated by the clinical phenotype and the lymphocyte subset enumeration.

Phenotype and function of the T cell compartment. T cell counts were also severely reduced, with the reduction in $\mathrm{CD} 4^{+} \mathrm{T}$ cell levels being more pronounced than that in $\mathrm{CD}^{+} \mathrm{T}$ cells (Figure 3). The proportion of "naive" $\mathrm{CD} 4^{+} \mathrm{T}$ cells coexpressing CD45RA and CD62L was very low, and a high percentage of $C D 8^{+} \mathrm{T}$ cells expressed HLA-DR, indicating a highly activated $\mathrm{T}$ cell compartment. Interestingly, $66 \%$ of $\mathrm{CD}^{+} \mathrm{T}$ cells expressed the $\gamma \delta \mathrm{T}$ cell receptor and only $32 \%$ the $\alpha \beta \mathrm{T}$ cell receptor. Twenty percent of TCR $\alpha \beta$ cells and $88 \%$ of $\gamma \delta$ TCR cells were double negative for CD4 and CD8 expression. HLA-DR and CD45RA expression was similar between the 2 populations (Figure 3). T cell proliferation was absent to Tetanus antigen and reduced after stimulation with phytohemagglutinin (PHA) (21,661 vs. $>40,000 \mathrm{cpm}$ in controls) or anti-CD3 (16,960 vs. $>34,000 \mathrm{cpm}$ ) but could be strongly induced by IL-2 stimulation $(33,736$ vs. $>1,000 \mathrm{cpm})$. To analyze the proliferative capacity of various $\mathrm{T}$ cell populations separately, we used a flow-cytometric CFSE-based proliferation assay. Stimulation with anti-CD3/anti$\mathrm{CD} 28$ beads or with PHA only induced proliferation among $\mathrm{CD} 4^{+}$, but not among $\mathrm{CD}^{+} \mathrm{T}$, cells (Figure 4). Among the dividing $\mathrm{T}$ cells, expression of the $\gamma \delta$ TCR could not be demonstrated.

Analysis of $T$ cell receptor diversity. To characterize the $T$ cell repertoire of the patient, we first analyzed the expression of various $V \beta$ chains. There was a significantly skewed repertoire, with preferential expression of $\mathrm{V} \beta 3$ and $\mathrm{V} \beta 28$ among $\mathrm{CD} 8^{+} \mathrm{T}$ cells (Figure $5 \mathrm{~A}$ ). The patient did not have a sufficient number of $\mathrm{CD}^{+} \mathrm{T}$ cells for this analysis. For a more detailed study of $\mathrm{T}$ cell receptor diversity, complementarity-determining region-3 (CDR3) spectratyping of some $\mathrm{V} \beta$ families was performed. Most of the $10 \mathrm{~V} \beta$ elements analyzed showed an oligoclonal skewing (Figure 5B). The analysis of some elements (Vß11, -14, -15, -20) also revealed the presence of single peaks, demonstrating the existence of predominant clones expressing these particular $V \beta$ chains. The presence of such predominant clones was confirmed by heteroduplex analysis (Figure 6).

Analysis of $\mathrm{V} \gamma$ and $V \delta$ chain expression revealed that $76 \%$ of $\gamma \delta \mathrm{T}$ cells used the V 83 element and $89 \%$ used the V $\gamma 4$ element (Figure 7, A and C). CDR3 spectratyping was also established for $\gamma \delta$ T cells and revealed an oligo- to polyclonal repertoire of cells using the $V \delta 1$ and V $\delta 2$ segments (Figure 7B). In contrast, among cells expressing the V $\delta 3$ chain, there was a significantly restricted spectrum with a highly oligoclonal profile of cells using the V83J 81 element (Figure 7B). Spectratyping analysis of the TCR $\gamma$ chain was performed with primers for $\mathrm{V} \gamma 4$, for the $\mathrm{V} \gamma \mathrm{I}$ subgroup (for detection of the functional genes $V \gamma 2,-3,-4,-5$, and -8 ), and subgroup II (specific for $\mathrm{V} \gamma 9)$. Elements of both subgroups were used in a highly restricted length profile (Figure 7D). The similar profile obtained with the $\mathrm{V} \gamma 4$ and the $\mathrm{V} \gamma$ subgroup I primer confirmed the preferential usage of the V $\gamma 4$ element as shown by flow cytometry.

To analyze the $\gamma \delta \mathrm{T}$ cell repertoire at a molecular level, $\gamma \delta \mathrm{TCR}^{+}$ PBLs were purified and cloned by limiting dilution. TCR $\gamma$ and $\delta$ sequences were obtained from these clones and from the PCR products amplified for the spectratyping analysis. $V \gamma 4$ sequences were detected in $7 / 8$ of the PCR products and $5 / 5$ of the clone sequences (Figure 8), confirming the flow cytometry and spectratyping data. Although a predominant sequence was found, a polyclonal background could clearly be demonstrated, revealing a more diverse spectrum at the molecular level (Figure 8). Analysis
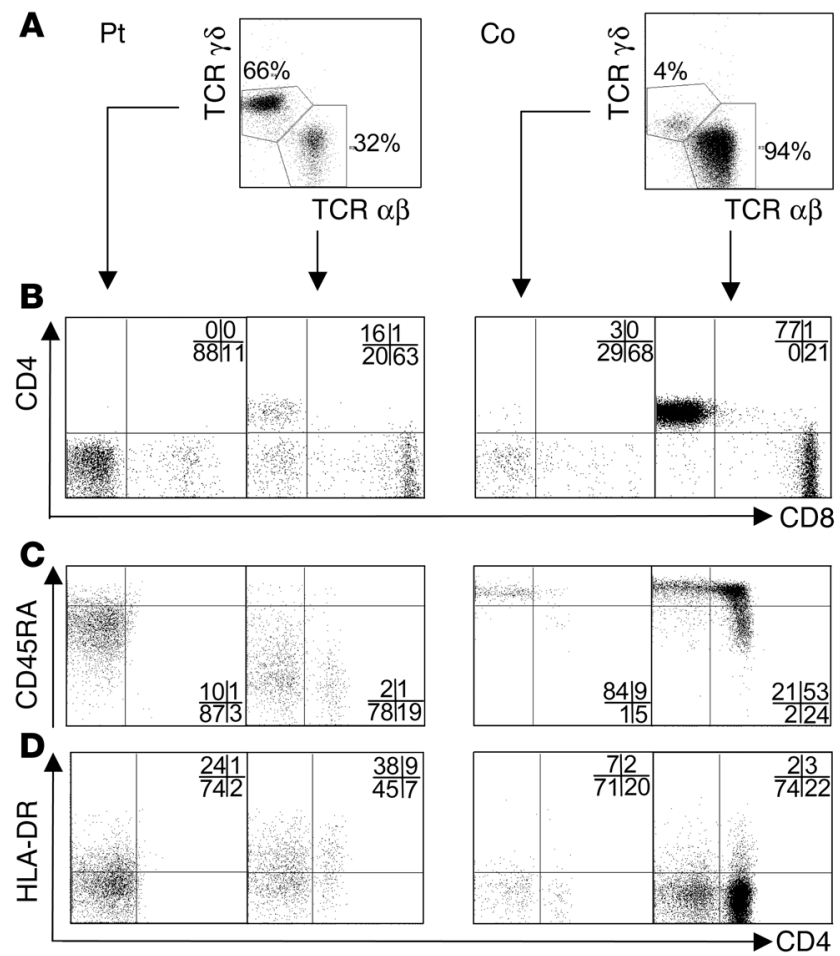

Figure 3

Predominance of activated $\gamma \delta$ T cells. (A) TCR expression among CD3 ${ }^{+}$ lymphocytes in the patient and a healthy control. (B) Expression of CD4 and CD8 among CD3 ${ }^{+} \mathrm{TCR} \alpha \beta^{+}$and $\mathrm{CD} 3^{+} \mathrm{TCR} \gamma \delta^{+} \mathrm{T}$ cells. (C) Expression of CD4 and CD45RA among CD3 ${ }^{+} \mathrm{TCR} \alpha \beta^{+}$and CD3 ${ }^{+} \mathrm{TCR} \gamma \delta^{+} \mathrm{T}$ cells. (D) Expression of CD4 and HLA-DR among CD $3^{+} \mathrm{TCR} \alpha \beta^{+}$and $\mathrm{CD}^{+} \mathrm{TCR} \gamma \delta^{+} \mathrm{T}$ cells. 


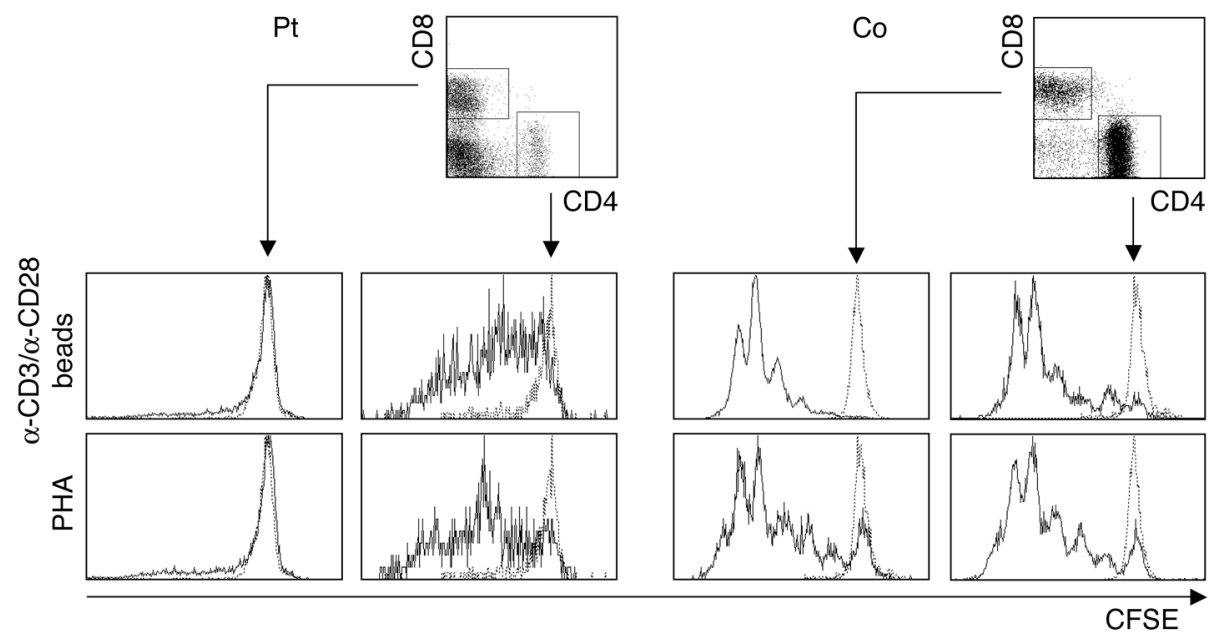

\section{Figure 4}

$\mathrm{T}$ cell proliferative responses. PBMCs from the patient and a healthy control were labeled with the fluorescent dye CFSE and incubated in medium or stimulated with PHA or with anti-CD3/ anti-CD28 beads. Five days later, cells were stained with anti-CD4 and anti-CD8 and analyzed by flow cytometry. CFSE dilution is plotted as an overlay of cells incubated in medium (dotted line) versus cells incubated with the indicated stimulus (bold line). of $\delta$ sequences revealed some complex junctional regions with 1 or $2 \mathrm{D}$ elements, while 2 sequences lacked D elements. All 3 clones used the V $\delta 3$ element, which was also predominantly expressed by peripheral $\gamma \delta \mathrm{T}$ cells.

$V \delta 2^{-} \gamma \delta T$ cells show reactivity against $C M V$-infected fibroblasts. Since the patient had undergone several viral infections prior to the immunological analysis, it appeared possible that the configuration of the $\gamma \delta$ T cell repertoire could have been influenced by these infections. In consideration of the observation that $V \delta 2^{\text {neg }}$ $\gamma \delta \mathrm{T}$ cell clones from $\mathrm{CMV}$-infected kidney transplant recipients display reactivity against CMV (7), we tested whether $\gamma \delta$ T cells from our patient were able to recognize CMV-infected target cells. Thus, we incubated various $V \delta 2^{-} \gamma \delta \mathrm{T}$ cell clones from the patient and a healthy control with CMV-infected and uninfected human foreskin fibroblasts (HFFs). In addition, we examined 2 V $\gamma 9-V \delta 2$ $\mathrm{T}$ cell clones from healthy controls. After 24 hours of coincubation with the target cells, TNF production was quantified in a biological assay using WEHI cells (43). Four of 5 clones from the patient produced significant amounts of TNF in response to CMV stimulation (Figure 9). CMV-specific TNF production was also found by $V \delta 2^{-} \gamma \delta \mathrm{T}$ cell clones from a healthy donor but - as expected - not by the $2 \mathrm{~V} \gamma 9-\mathrm{V} \delta 2$ clones.

\section{Discussion}

We document a new variant of SCID associated with a hypomorphic RAG1 mutation that includes normal levels of immunoglobulins, the ability to produce specific antibodies to infectious and self-antigens, and a predominance of $\gamma \delta$ T cells.

Our patient fulfilled the clinical criteria for SCID, including failure to thrive, persistent candida infection, recurrent pneumonia, and severe infections with varicella-zoster virus (VZV), CMV, and EBV. There was also profound lymphopenia, with an almost

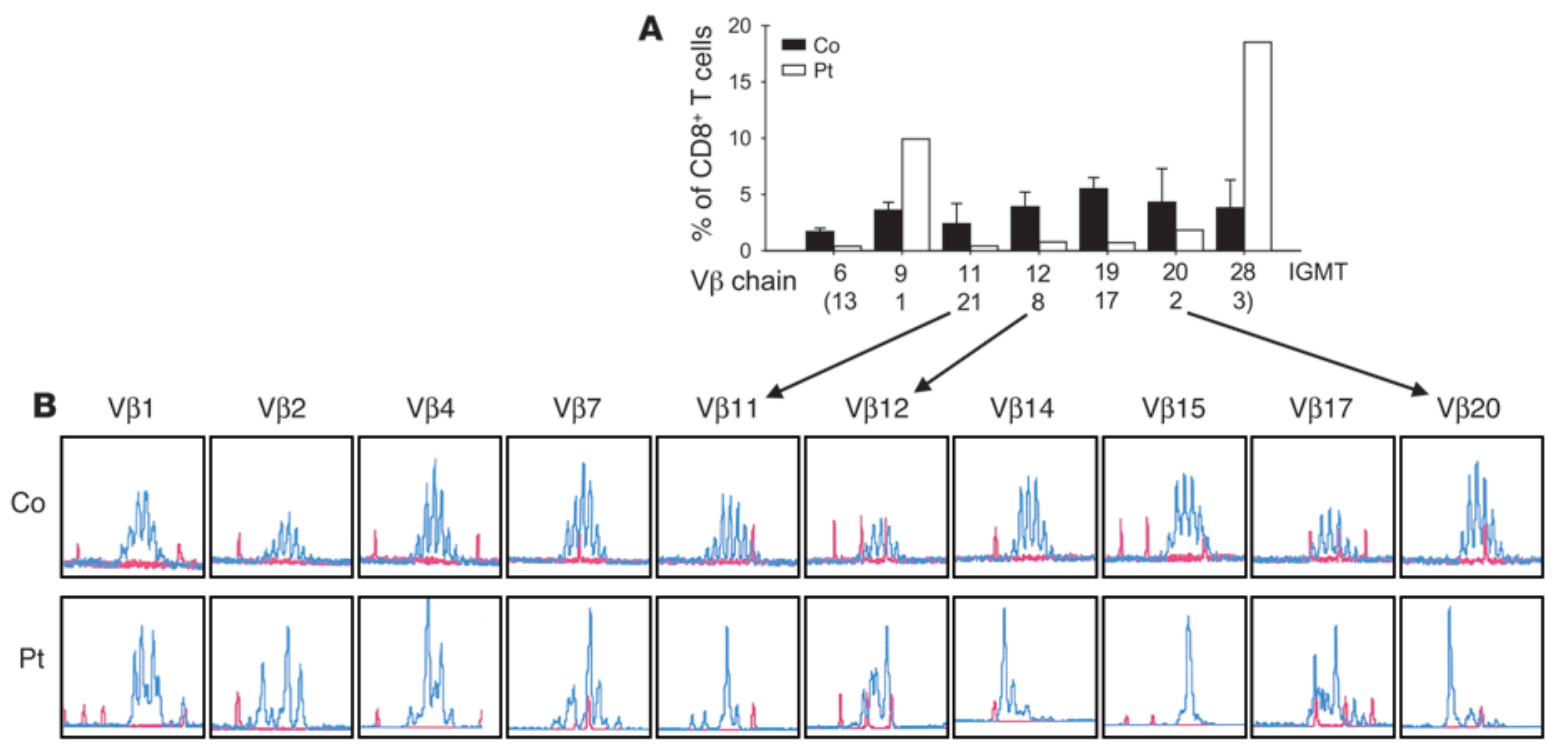

Figure 5

$\mathrm{T}$ cell repertoire. (A) V $\beta$ chain expression among CD8 ${ }^{+} \mathrm{T}$ cells as determined by flow cytometry. (B) CDR3 length profile of various $\mathrm{V} \beta$ populations as determined by immunoscope analysis. The relative intensity of the bands is plotted as a function of CDR3 size. Since the nomenclature of the used antibodies is based on Wei et al. (37), the corresponding IGMT nomenclature is also provided in order to correlate the cytometry data with spectratyping results. 
$\mathrm{Pt}$

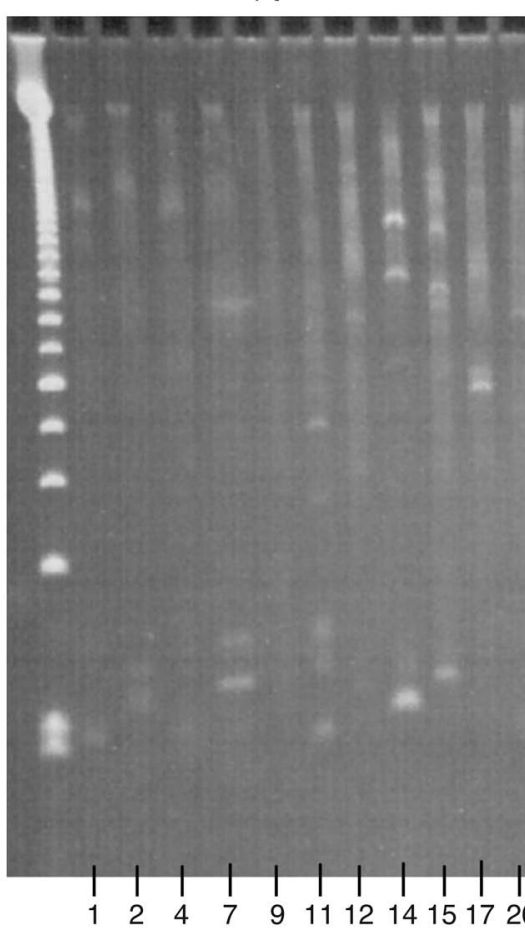

Co

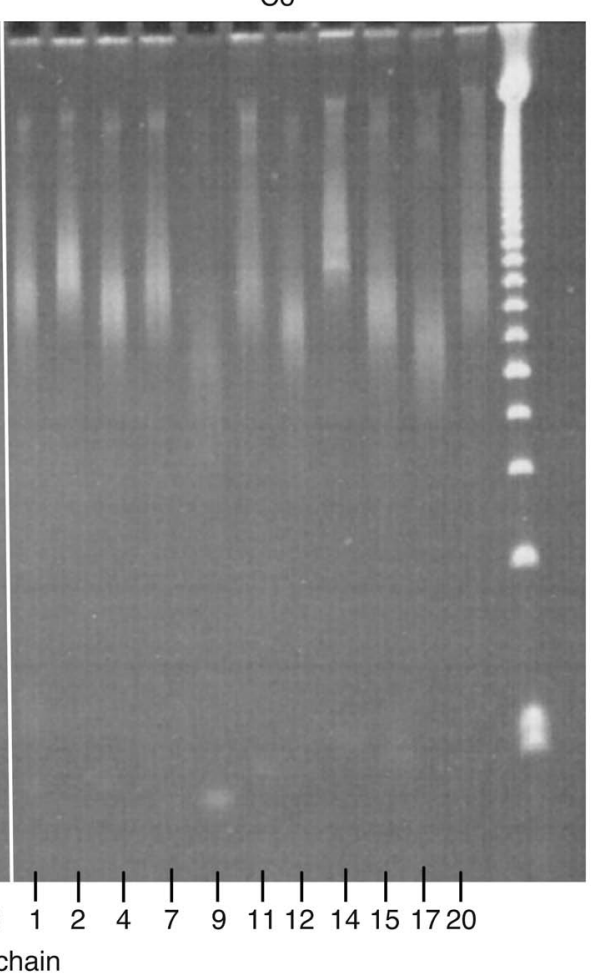

Figure 6

Oligoclonal T cell expansions. Heteroduplex analysis of PCR products was performed by nondenaturing PAGE and visualized by ethidium bromide staining.

$\mathrm{N}$-terminal from the $\mathrm{R} 561 \mathrm{H}$ mutation exhibited by our patient. The data indicate that partial RAG1 function due to mutations in the RAG1/RAG2 interaction domain affects $B$ cell differentiation and repertoire diversity but still allows development of some functional B cells. This is also supported by the finding of in-frame immunoglobulin rearrangements in bone marrow precursor B cells of a patient with an H481P RAG1 mutation and a T-B-SCID phenotype (9). The presence of autoantibodies in our and the previously reported patient could be due to impaired $\mathrm{T}$ cell regulation. However, it is also possible that this reflects the described role for RAG enzymes in the regulation of autoantibodies by receptor editing (10).

Patients with hypomorphic RAG mutations presenting with OS typically show a high number of circulating $T$ cells with a highly restricted $\mathrm{T}$ cell repertoire (11-14).

complete absence of B cells and severely reduced numbers of $\mathrm{T}$ cells and a small thymus. However, normal to elevated levels of all immunoglobulin classes and specific IgM and IgG antibodies to some vaccine antigens and infectious agents indicated significant remaining B and T cell function, atypical for SCID. Antibody responses against diphtheria antigen, VZV, and CMV but not against tetanus and EBV suggested a restricted repertoire of $B$ cell specificities. The production of specific antibodies to diphtheria vaccination, HSV-1 infection, and neutrophil autoantigens has previously been observed in a patient with atypical RAG1 SCID, who had maternal $\mathrm{T}$ cell engraftment but lacked host $\mathrm{T}$ cells (8). That patient carried the R559S mutation only 2 amino acids
The predominance of few $\mathrm{T}$ cell receptor clonotypes is already detectable in the thymus, and a different distribution of clonotypes can be found in different tissues, suggesting that in OS, the oligoclonality of the $\mathrm{T}$ cell repertoire is due to both intrathymic restriction and peripheral expansion $(12,15)$. Among the few $\alpha \beta$ TCR T cells detectable in our patient, $\mathrm{CD}^{+} \mathrm{T}$ cells predominated. TCR V $\beta$ spectratyping and heteroduplex analysis revealed a reduced repertoire diversity, with oligoclonal $\mathrm{T}$ cell expansions similar to what has been described in OS, which shows that such $\mathrm{T}$ cell repertoire restrictions in RAG deficiency are not necessarily linked to development of the Omenn phenotype. Interestingly, the $\mathrm{CD}^{+} \mathrm{T}$ cells in our patient were completely refractory to mitogen
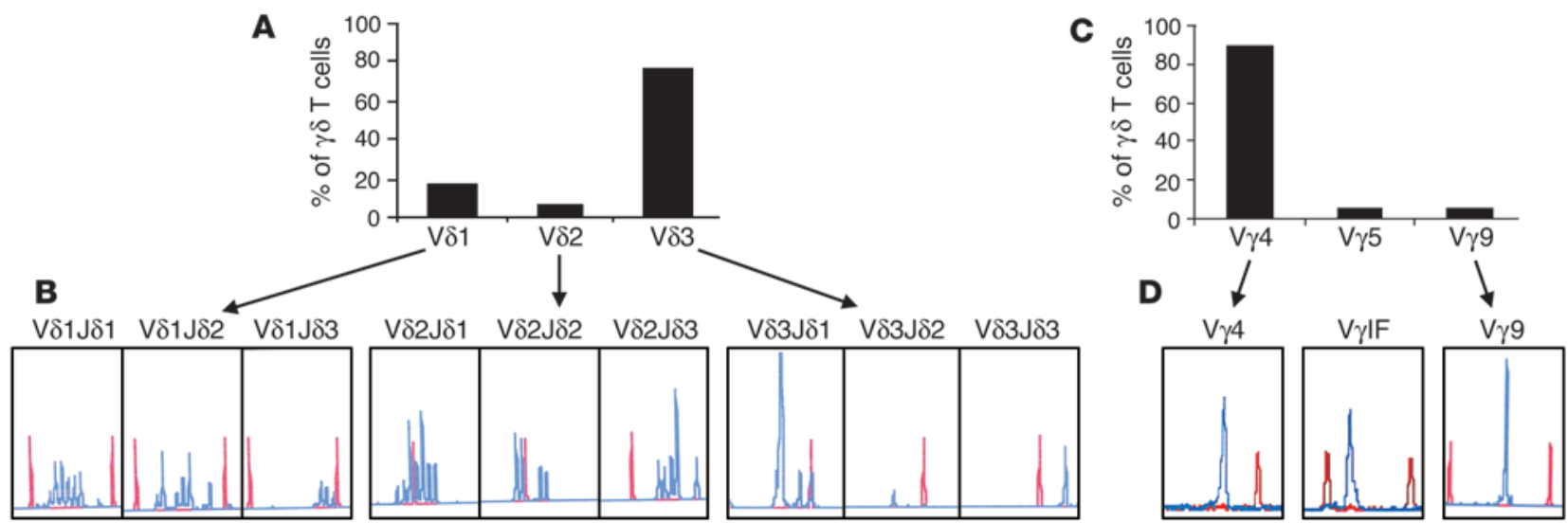

Figure 7

$\gamma \delta \mathrm{T}$ cell repertoire analysis. (A) V $\delta$ chain usage among total $\gamma \delta \mathrm{TCR}+\mathrm{CD} 3^{+} \mathrm{T}$ cells. (B) CDR3 length profile of V $\delta 1-\mathrm{V} \delta 3$ populations using

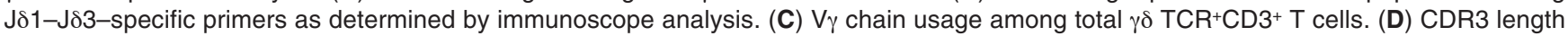
profile of $V_{\gamma}$ populations using primers specific for $V_{\gamma} 4, V_{\gamma} I F$ (specific for subgroup I), and $V_{\gamma} 9$ (specific for subgroup II). 


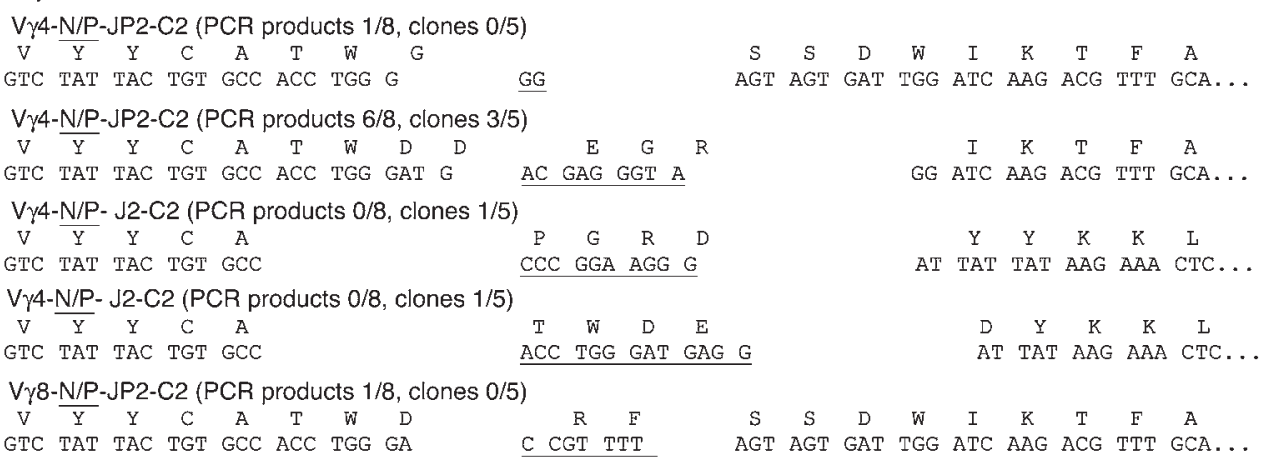

$\delta$

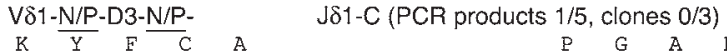

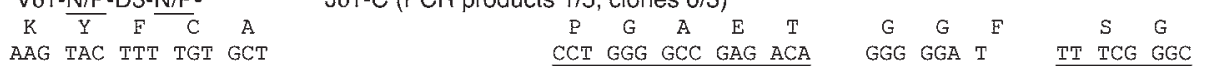

V81-N/P-D3-N/P-D2(?)-N/P-J81-C (PCR products 1/5, clones 0/3)

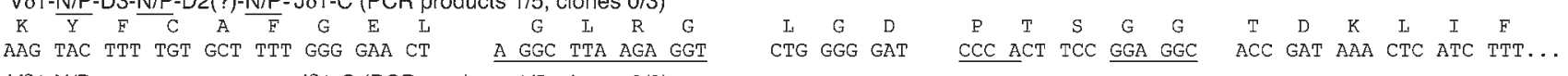

$V \delta 1-N / P$ - $\quad J 81-C$ (PCR products $1 / 5$, clones $0 / 3)$

K $\frac{Y}{Y} \quad F \quad C \quad A \quad L \quad G \quad E \quad$ D $\quad F \quad S \quad G \quad K$

AAG TAC TTT TGT GCT CTT GGG GAA GAT TTC TCG GGG AAG

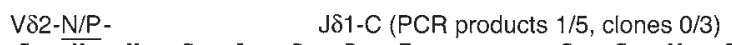

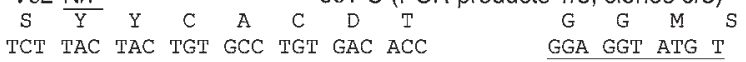

V82-N/P-D3-N/P- J61-C (PCR products $1 / 5$, clones $0 / 3$ )

$S \frac{Y}{Y} C_{A} \quad C \quad D \quad T \quad M \quad G \quad L$

TCT TAC TAC TGT GCC TGT GAC AC G ATG GGA GGT C

V83-N/P-D3(?)-N/P. J81-C (PCR products $0 / 5$, clones $3 / 3$ )

$\begin{array}{cccccc}T & Y & Y & \bar{C} & A & \\ \text { ACT } & \text { TAC } & \text { TAC } & \text { TGT } & \text { GCC } & \text { T }\end{array}$

TC CCG G

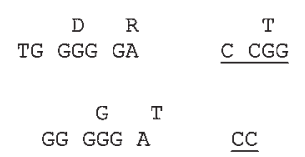

$\begin{array}{cccccc}\text { T } & \text { D } & K & \text { L } & \text { I } & \text { F } \\ \text { ACC } & \text { GAT } & \text { AAA } & \text { CTC } & \text { ATC } & \text { TTT... }\end{array}$

Figure 8

$\mathrm{V}(\mathrm{D}) \mathrm{J}$ junction sequences of $\gamma \delta \mathrm{T}$ cells. The $\mathrm{V}(\mathrm{D}) \mathrm{J}$ segments identified are indicated in bold; $\mathrm{N}$ sequences are underlined. The number of times a sequence was found among PCR products and among clone sequences is given in parenthesis.

stimulation in vitro. This may represent anergy in the context of severe EBV infection rather than an intrinsic T cell defect. In contrast, the few residual $\mathrm{CD}^{+} \mathrm{T}$ cells showed proliferation in vitro and were apparently sufficient to provide B cell help in vivo.

A striking feature in our patient was the predominance of T cells expressing the $\gamma \delta \mathrm{T}$ cell receptor. This has also been described in a few patients with OS $(13,15-17)$. One patient showed expression of V 1 in $35 \%$ of $\mathrm{T}$ cells, while expression of the more commonly used $V \gamma 9$ and $V \delta 2$ chains was not detected. These V $\delta 1$-expressing cells could also be found in the epidermis and in the gut (13). A second patient preferentially used the $\mathrm{V} \gamma 3$ and $V \gamma 4$, but not $V \gamma 9$, genes (16). Lack of the $V \gamma 9 \mathrm{~V} \delta 2 \mathrm{~T}$ cell subset usually predominant in peripheral blood $(18,19)$ was also observed in our patient, whose main $\gamma \delta \mathrm{T}$ cell population expressed $V \gamma 4 \mathrm{~V} \delta 3$. What could be the reason for the $\gamma \delta \mathrm{T}$ cell predominance in these patients? It is unlikely that limited RAG activity predominantly affects the generation of functional T cell receptors in $\alpha \beta$ as compared with $\gamma \delta \mathrm{T}$ cells. However, the limited $\mathrm{T}$ cell receptor repertoire generated with a dysfunctional recombination machinery may have consequences for $\mathrm{T}$ cell development. A comparison of thymic and peripheral $\mathrm{T}$ cell receptor sequences showed that the skewed $\mathrm{T}$ cell repertoire in OS is partially shaped by intrathymic restriction (15). With respect to $\alpha \beta$ versus $\gamma \delta$ T cell development, this could imply that the more stringent intrathymic maturational restriction for $\alpha \beta \mathrm{T}$ cells could account for the predominance of $\gamma \delta \mathrm{T}$ cells in patients with recom- bination defects. Moreover, since the repertoire of $\gamma \delta \mathrm{T}$ cells, in particular in nonlymphoid tissues, is often oligoclonal $(20,21)$, a limited number of successful recombination events may be sufficient to generate an apparently normal $\gamma \delta \mathrm{T}$ cell repertoire. The $\gamma \delta$ $\mathrm{T}$ cell repertoire may also be influenced by the severe reduction in the number of $\alpha \beta$ T cells. TCR $\alpha$-deficient mice, which completely lack $\alpha \beta$ T cells, show normal numbers of $\gamma \delta$ T cells (22) that expand significantly more after exposure to environmental antigens than in mice with a normal $\alpha \beta$ T cell compartment (23).

Apart from these developmental considerations, there is significant evidence that extrinsic and environmental factors further shape the peripheral $\gamma \delta$ T cell repertoire (24). Expansion of $\gamma \delta$ T cells has been observed in the context of various viral infections, including EBV and CMV (25-27). In particular, a recent report has shown that $V \delta 2^{-} \gamma \delta \mathrm{T}$ cell clones show reactivity against $\mathrm{CMV}$-infected cells (7). We could also document a response to CMV-infected cells in $4 / 5$ clones from our patient, which could reflect an important impact of CMV on the $\gamma \delta \mathrm{T}$ cell predominance. It remains open whether this reactivity is directed against a viral antigen or a virally induced cellular antigen such as a stress protein (24). The fact that $2 / 3 \mathrm{~V} \delta 2^{-}$, but not $2 / 2 \mathrm{~V} \gamma 9-\mathrm{V} \delta 2$, clones from healthy controls with unknown CMV status also responded to CMV-infected cells supports the idea of a predetermined specificity $(28,29)$ of a significant proportion of human $\mathrm{V} \delta 2^{-} \gamma \delta \mathrm{T}$ cells for conserved noninfectious antigens. We found a more restricted variability of $\delta 3$ versus 


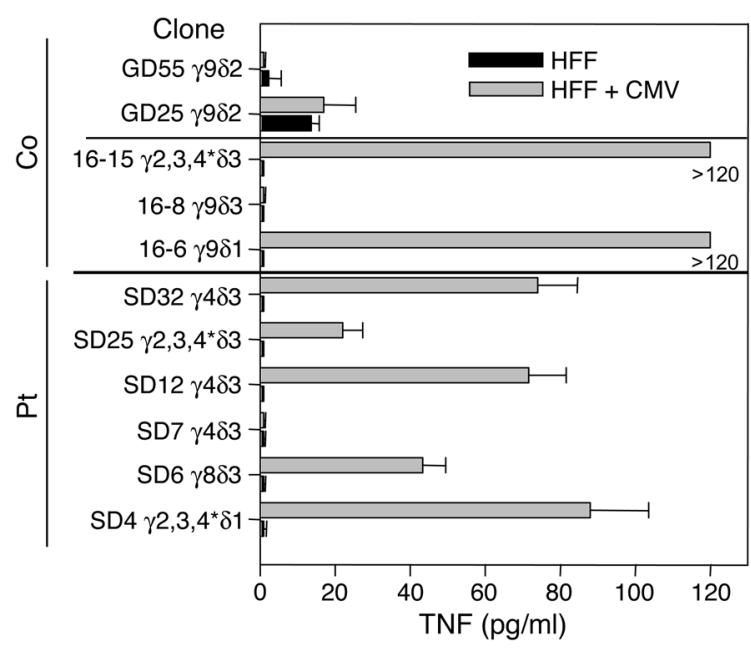

Figure 9

CMV reactivity of $\mathrm{V} \delta 2^{-} \gamma \delta \mathrm{T}$ cell clones. Two $\mathrm{V} \gamma 9-\mathrm{V} \delta 2$ and $3 \mathrm{~V} \delta 2^{-} \mathrm{V} \gamma 9^{-}$ clones from healthy controls as well as $6 \gamma \delta$ T cell clones using different combination of $\mathrm{T}$ cell receptors from the patient were tested for CMV reactivity. $\gamma \delta$ TCR usage of the clones was analyzed with various antibodies. The clones were incubated with $\mathrm{CMV}$-infected and uninfected fibroblasts, and TNF release was quantified in a bioassay on WEHI cells (43). *The antibody used for characterization of these clones reacts with all $3 \gamma$ chain proteins.

$\delta 1$ and $\delta 2$ elements and a seemingly monoclonal usage of the $V \gamma 4$ element by spectratyping, suggesting selection by antigens such as those induced by CMV infection. However, the dominance of the $\mathrm{V} \gamma 4$ and $V \delta 3$ elements is seen in a clearly oligoclonal background of $\gamma \delta \mathrm{T}$ cells. Even among V $\gamma 4 \mathrm{~T}$ cells, significant sequence heterogeneity could be demonstrated at the molecular level, revealing development of a $\gamma \delta \mathrm{T}$ cell repertoire with significant diversity. Overall, the results of the $\gamma \delta$ T cell repertoire analysis in our patient are compatible both with a developmental advantage and with infectious or autoantigen-driven peripheral expansion as 2 nonmutually exclusive explanations for the $\gamma \delta \mathrm{T}$ cell predominance.

Two RAG1-deficient patients were previously reported to carry the same homozygous $\mathrm{R} 561 \mathrm{H}$ mutation $(4,6)$. This mutation lies within a region of RAG1 that mediates interaction with RAG2 (30) and decreases efficiency of interaction by about $80 \%$, leading to a residual recombination activity of roughly $25 \%$ (4). Lymphocyte subset enumeration in the 3 patients was similar, with an almost complete absence of B cells, a reduced number of T cells, and a normal level of NK cells, likely reflecting the consequences of impaired $\mathrm{V}(\mathrm{D}) \mathrm{J}$ recombination for lymphocyte development (Table 1 ). The clinical and functional immunological phenotype, however, was different and characteristic in all 3 patients. Patient OS2 presented with OS including erythroderma, lymphoproliferation, as well as elevated levels of $\operatorname{IgE}$ and eosinophilia. $\operatorname{IgA}$ and $\operatorname{IgM}$ were absent, and the level of IgG was low at the age of 2 months and likely represented transferred maternal antibody. Specific antibodies were absent $(31,32)$. Patient P27 presented with pharyngeal and genital ulcers, a phenotype frequently associated with Artemis mutations (33). Features of OS were absent, but this patient showed production of immunoglobulins including autoantibodies. Our patient presented with severe herpes virus infections, also produced immunoglobulins and autoantibodies, and showed a characteristic predominance of $\gamma \delta \mathrm{T}$ cells. It remains speculative to what extent modifying genes including autoantigens and/or environmental factors such as infections (34) influenced the phenotypic expression of the immunodeficiency. However, it seems reasonable to assume that in patients with a rudimentary specific immune system - presumably including absence of regulatory cells - exposure to autoantigens or persistent infections leaves "footprints" that determine the distinct clinical and immunologic phenotype. Autoantibody production, activation of oligoclonal T cells and a Th2-type immune response, and $\gamma \delta \mathrm{T}$ cell predominance could represent such footprints, triggered by antigen and clinically manifest due to lack of regulation.

This and other recent reports on genetic defects of the $V(D) J$ recombination machinery $(5,6,35,36)$ paradigmatically illustrate the large phenotypic variability of patients with primary immunodeficiencies, which is determined by both genetic and environmental factors. The type of mutation is an important determinant whether RAG-deficient patients present with $\mathrm{T}^{-} \mathrm{B}^{-} \mathrm{SCID}$ (null mutations) or with OS/atypical SCID/SCID with $\gamma \delta \mathrm{T}$ cell predominance (hypomorphic mutations). Genetic heterogeneity is demonstrated by the recent description of an Omenn phenotype in a patient with a hypomorphic mutation in Artemis (35). In addition, we recently diagnosed SCID with $\gamma \delta \mathrm{T}$ cell predominance, autoantibodies, and EBV-induced lymphoproliferation strikingly similar to those in the patient reported here in a patient with a hypomorphic mutation in ligase $I V$, another enzyme involved in $\mathrm{V}(\mathrm{D}) \mathrm{J}$ recombination (A. Enders, unpublished observations). Finally, the impact of further genetic modifiers and/or environmental factors, infections in particular, is well illustrated by the 3 distinct phenotypes of the patients with homozygous R561H mutations described in this report. Unfortunately, since the clinical diagnosis is usually made in a child with a history of severe infections, it is frequently impossible to separate defects in immune development from the phenotypic consequences of impaired antimicrobial defense and defects in immune regulation. A better understanding of the contribution of genetic versus environmental factors will therefore probably depend on the study of mice with equivalent missense mutations. From a clinical viewpoint, however, awareness of the phenotypic variability is instrumental for the life-saving early identification of such patients.

\section{Methods}

Immunophenotyping. Informed consent for the performed studies was obtained from the patient's family, in accordance with the guidelines of the ethics committee of the University of Freiburg. Lymphocyte phenotyping was performed with 4-color flow cytometry using antibodies from BD Biosciences - Pharmingen. TCR V $\beta$ staining was performed using a panel of antibodies obtained from Immunotech, Beckman Coulter. The nomenclature of these antibodies is based on Wei et al. (37). For TCR V $\gamma$ and $V \delta$ staining, we used indirect fluorescence with the mAbs anti-TCR

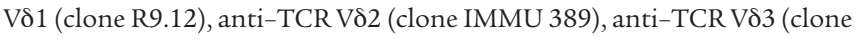
D3P11.5B), and anti-TCR V $\gamma 9$ (clone IMMU 360; all from Immunotech, Beckman Coulter); anti-TCR V $\gamma 4$ (clone 94) and anti-TCR V $\gamma 5$ (clone 563; both kindly provided by Marc Bonneville, Institut National de la Santé et de la Recherche Médicale, U463, Nantes, France); anti-TCR V $\gamma 8$ (clone R4-5) and anti-TCR V $\gamma 2$, -3, and -4 (clone 23D12; both kindly provided by Dieter Kabelitz, Institute of Immunology, University of Kiel, Kiel, Germany). T cell proliferation was quantified using a standard $\left[{ }^{3} \mathrm{H}\right]$ thymidine incorporation and a CFSE proliferation assay. For this, $5 \times 10^{6} \mathrm{PBMCs}$ were labeled with the fluorescent dye CFSE (Invitrogen Corp.) for 10 minutes and washed twice with ice-cold PBS. CFSE-labeled PBMCs $\left(2.5 \times 10^{5}\right)$ in 
a volume of $200 \mu \mathrm{l}$ Iscove's Modified Dulbecco's Medium 10\% FCS were stimulated either with phytohemagglutinin $(1.25 \mu \mathrm{g} / \mathrm{ml})$ or with anti$\mathrm{CD} 3 /$ anti-CD28 beads (Dynal Biotech) at $37^{\circ} \mathrm{C}$. Control cells were cultivated in medium alone. On day 6 , the cells were harvested; washed; surface stained with anti-CD3, anti-CD4, and anti-CD8 or anti-CD3 and anti- $\gamma \delta$ TCR antibodies; and analyzed by flow cytometry on a BD FACSort using CellQuest Pro software version 4.0.2.

Tcell CDR3 spectratyping. TCR CDR3 spectratyping was performed as previously described by Pannetier, Kourilsky, et al. for the analysis of the TCR $\beta$ chain $(38,39)$. The primers for spectratyping of the TCR $\gamma$ and TCR $\delta$ chains were newly designed: the PCR ( 30 cycles) for analysis of the TCR $\delta$ chain was performed using the forward primers TRDV1F ( $5^{\prime}$-ATGCAAAAAGTGGTCGCTATT-3'), TRDV2F (5'-ATACCGAGAAAAGGACATCTATG-3'), TRDV3F ( $5^{\prime}$-GTACCGGATAAGGCCAGATTA-3'), TRDV4F (5'-ATGACCAGCAAAATGCAACAG-3'), TRDV5F (5'-ACCCTGCTGAAGGTCCTACAT-3'), and TRDV6F (5'-CCCTGCATTATTGATAGCCAT- $\left.3^{\prime}\right)$ and the reverse primer TRDCB (5'- GTAGAATTCCTTCACCAGACAAG-3'), followed by run-off analysis ( 3 cycles) using the fluorescent primers J $\delta 1$, $\mathrm{J} \delta 2$, and $\mathrm{J} \delta 3$, as published in the BIOMED-2 protocol (40). The PCR (30 cycles) for analysis of the TCR $\gamma$ chain was performed using the forward primers TRGV1F (5'-GGAAGGCCCCACAGCRTCTT-3'), TRGV4F (5'ATGACTCCTACACCTCCAGC-3'), and TRGV9F (5'-CGGCACTGTCAGAAAGGAATC- $\left.3^{\prime}\right)$ and the reverse primer TRGCB (5'-CAAGAAGACAAAGGTATGTTCCAG-3'), followed by run-off analysis (3 cycles) with the fluorescent oligonucleotide TRGCRO (5'-CTTCTGGAGYTTTGTTTCAGC-3'). All primers were chosen according the sequences and primers in the ImMunoGeneTics database (http://imgt.cines.fr/textes/ IMGTrepertoire). The primers TRDV4F-6F and the primer TRVG9F were the same as published in the BIOMED-2 protocol (40). Heteroduplex analysis was performed according to published protocols (41).

Derivation and characterization of $\gamma \delta$ T cell clones. TCR $\gamma \delta^{+}$PBLs of the patient were purified by magnetic beads ( $\gamma \delta \mathrm{T}$ cell isolation kit; Miltenyi Biotec). The clones were derived by limiting dilution using feeder cells, PHA, and IL-2 and expanded as previously described (42). The phenotype and $V$ regions of the $\gamma \delta$ TCR expressed by the clones were analyzed by flow cytometry using the mAbs described above and confirmed by TCR $\gamma$ and $\delta$ spectratyping. RNA was extracted from the clones for sequence analysis of the TCR $\gamma$ and $\delta$ chains.

Analysis of CMV reactivity of $\gamma \delta T$ cell clones. CMV suspensions produced with the clinical strain TB40/E and HFFs were kindly provided by C.
Sinzger, University of Tübingen, Tübingen, Germany. Subconfluent monolayers of HFF cells were incubated with CMV suspension at an MOI of 1 for 1 hour and cultured for 5 days at $37^{\circ} \mathrm{C}$. Thawed $\gamma \delta \mathrm{T}$ cell clones that had been cultured in the presence of allogeneic feeder cells and $50 \mathrm{IU} / \mathrm{ml} \mathrm{IL-2}$ were incubated $\left(2 \times 10^{3}\right.$ cells/well) with CMV-infected or noninfected HFFs $\left(2 \times 10^{5}\right.$ cells/well $)$ in a flat-bottom 96 -well plate at $37^{\circ} \mathrm{C}$ for 6 hours. TNF released into the supernatant was quantified in a bioassay using WEHI cells as described previously (43).

Histology and molecular analysis of clonality. Biopsy samples were fixed in $4 \%$ buffered formalin, paraffin-embedded, cut at $4 \mu \mathrm{m}$, and stained immunohistochemically following heat-mediated antigen retrieval. The primary antibodies were obtained from DakoCytomation and included CD20 (clone L26), CD3 (clone F7.2.38), CD4 (clone MT310), CD8 (clone C8/144B), CD21 (clone 1F8), CD30 (clone Ber-H2), CD79a (clone JCB117), Ki 67 (clone MIB-1), BCL2 oncoprotein (clone 124), BCL6 protein (clone PG-B6p), and EBV LMP (clone CS.1-4). Visualization of the antibodies was obtained using the ChemMate Detection Kit, AP/RED (DakoCytomation). IgH gene configuration in lymphoproliferative lesions was assesses by multiplex PCR from DNA isolated from biopsy specimen using a previously described method (44).

Genetic analysis. The molecular analyses of the RAG genes were performed as published previously (45).

\section{Acknowledgments}

We thank C. Sinzger for providing CMV suspensions and HFF cells. We are grateful to Peter Bader, Children's Hospital, Frankfurt University, Germany, for data on chimerism and to Olaf Moske, Department of Radiology, Freiburg University, Germany, for providing the CT scan. We thank Daniela Bukatz, Ingrid Janz, Sylvia Kock, and Annette Schult for excellent technical assistance. This work was supported by the German Research Foundation grant SFB620: Immunodeficiency: clinical and animal models (projects A4 [S. Ehl] and Z2 [P. Fisch]).

Received for publication March 21, 2005, and accepted in revised form July 19, 2005.

Address correspondence to: Stephan Ehl, Department of Pediatrics and Adolescent Medicine, University of Freiburg, Mathildenstr. 1, 79106 Freiburg, Germany. Phone: 49-761-270-4301; Fax: 49-761270-4481; E-mail: ehl@kikli.ukl.uni-freiburg.de.
1. Buckley, R.H. 2004. Molecular defects in human severe combined immunodeficiency and approaches to immune reconstitution. Annu. Rev. Immunol. 22:625-655.

2. Buckley, R.H., et al. 1997. Human severe combined immunodeficiency: genetic, phenotypic, and functional diversity in one hundred eight infants. J. Pediatr. 130:378-387.

3. Omenn, G.S. 1965. Familial reticuloendotheliosis with eosinophilia. N. Engl. J. Med. 273:427-432.

4. Villa, A., et al. 1998. Partial V(D)J recombination activity leads to Omenn syndrome. Cell. 93:885-896.

5. Villa, A., et al. 2001. V(D)J recombination defects in lymphocytes due to RAG mutations: severe immunodeficiency with a spectrum of clinical presentations. Blood. 97:81-88.

6. Corneo, B., et al. 2001. Identical mutations in RAG1 or RAG2 genes leading to defective $V(D) J$ recombinase activity can cause either T-B-severe combined immune deficiency or Omenn syndrome. Blood. 97:2772-2776.

7. Halary, F., et al. 2005. Shared reactivity of Vdelta2(neg) gammadelta $T$ cells against cytomegalovirus-infected cells and tumor intestinal epithelial cells. J. Exp. Med. 201:1567-1578.
8. Kumaki, S., et al. 2001. Identification of anti-herpes simplex virus antibody-producing B cells in a patient with an atypical RAG1 immunodeficiency. Blood. 98:1464-1468.

9. Noordzij, J.G., et al. 2002. The immunophenotypic and immunogenotypic B-cell differentiation arrest in bone marrow of RAG-deficient SCID patients corresponds to residual recombination activities of mutated RAG proteins. Blood. 100:2145-2152.

10. Jankovic, M., Casellas, R., Yannoutsos, N., Wardemann, H., and Nussenzweig, M.C. 2004. RAGs and regulation of autoantibodies. Annu. Rev. Immunol. 22:485-501.

11. Brooks, E.G., Filipovich, A.H., Padgett, J.W., Mamlock, R., and Goldblum, R.M. 1999. T-cell receptor analysis in Omenn's syndrome: evidence for defects in gene rearrangement and assembly. Blood. 93:242-250.

12. Rieux-Laucat, F., et al. 1998. Highly restricted human $\mathrm{T}$ cell repertoire in peripheral blood and tissue-infiltrating lymphocytes in Omenn's syndrome. J. Clin. Invest. 102:312-321.

13. de Saint-Basile, G., et al. 1991. Restricted heterogeneity of T lymphocytes in combined immunodeficiency with hypereosinophilia (Omenn's syn- drome). J. Clin. Invest. 87:1352-1359.

14. Harville, T.O., Adams, D.M., Howard, T.A., and Ware, R.E. 1997. Oligoclonal expansion of $\mathrm{CD} 45 \mathrm{RO}+\mathrm{T}$ lymphocytes in Omenn syndrome. J. Clin. Immunol. 17:322-332.

15. Signorini, S., et al. 1999. Intrathymic restriction and peripheral expansion of the T-cell repertoire in Omenn syndrome. Blood. 94:3468-3478.

16. Mathioudakis, G., Good, R.A., Chernajovsky, Y., Day, N.K., and Platsoucas, C.D. 1996. Selective gamma-chain $\mathrm{T}$-cell receptor gene rearrangements in a patient with Omenn's syndrome: absence of V-II subgroup (V gamma 9) transcripts. Clin. Diagn. Lab. Immunol. 3:616-619.

17. Wirt, D.P., et al. 1989. Novel T-lymphocyte population in combined immunodeficiency with features of graft-versus-host disease. N. Engl. J. Med. 321:370-374.

18. Parker, C.M., et al. 1990. Evidence for extrathymic changes in the $\mathrm{T}$ cell receptor gamma/delta repertoire. J. Exp. Med. 171:1597-1612.

19. Dechanet, J., Merville, P., Pitard, V., Lafarge, X., and Moreau, J.F. 1999. Human gammadelta T cells and viruses. Microbes Infect. 1:213-217.

20. Heilig, J.S., and Tonegawa, S. 1986. Diversity of 
murine gamma genes and expression in fetal and adult T lymphocytes. Nature. 322:836-840.

21. Asarnow, D.M., et al. 1988. Limited diversity of gamma delta antigen receptor genes of Thy-1+ dendritic epidermal cells. Cell. 55:837-847.

22. Philpott, K.L., et al. 1992. Lymphoid development in mice congenitally lacking $\mathrm{T}$ cell receptor alpha beta-expressing cells. Science. 256:1448-1452.

23. Viney, J.L., et al. 1994. Lymphocyte proliferation in mice congenitally deficient in T-cell receptor alpha beta + cells. Proc. Natl. Acad. Sci. U. S. A. 91:11948-11952.

24. Carding, S.R., and Egan, P.J. 2002. Gammadelta T cells: functional plasticity and heterogeneity. Nat. Rev. Immunol. 2:336-345.

25. De Paoli, P., et al. 1990. Gamma delta T cell receptor-bearing lymphocytes during Epstein-Barr virus infection. J. Infect. Dis. 161:1013-1016.

26. Dechanet, J., et al. 1999. Implication of gammadelta $\mathrm{T}$ cells in the human immune response to cytomegalovirus. J. Clin. Invest. 103:1437-1449.

27. Lafarge, X., et al. 2001. Cytomegalovirus infection in transplant recipients resolves when circulating gammadelta $\mathrm{T}$ lymphocytes expand, suggesting a protective antiviral role. J. Infect. Dis. 184:533-541.

28. Shin, S., et al. 2005. Antigen recognition determinants of gammadelta $\mathrm{T}$ cell receptors. Science. 308:252-255

29. Adams, E.J., Chien, Y.H., and Garcia, K.C. 2005. Structure of a gammadelta $\mathrm{T}$ cell receptor in complex with the nonclassical MHC T22. Science. 308:227-231.

30. McMahan, C.J., Sadofsky, M.J., and Schatz, D.G.
1997. Definition of a large region of RAG1 that is important for coimmunoprecipitation of RAG2. J. Immunol. 158:2202-2210.

31. Brugnoni, D., et al. 1997. In vitro cell death of activated lymphocytes in Omenn's syndrome. Eur. J. Immunol. 27:2765-2773.

32. Chilosi, M., et al. 1996. CD30 cell expression and abnormal soluble CD30 serum accumulation in Omenn's syndrome: evidence for a T helper 2mediated condition. Eur. J. Immunol. 26:329-334.

33. Kwong, P.C., O'Marcaigh, A.S., Howard, R., Cowan, M.J., and Frieden, I.J. 1999. Oral and genital ulceration: a unique presentation of immunodeficiency in Athabascan-speaking American Indian children with severe combined immunodeficiency. Arch. Dermatol. 135:927-931.

34. Dalal, I., et al. 2005. Evolution of a T-B- SCID into an Omenn syndrome phenotype following parainfluenza 3 virus infection. Clin. Immunol. 115:70-73.

35. Ege, M., et al. 2005. Omenn syndrome due to ARTEMIS mutations. Blood. 105:4179-4186.

36. Moshous, D., et al. 2003. Partial T and B lymphocyte immunodeficiency and predisposition to lymphoma in patients with hypomorphic mutations in Artemis. J. Clin. Invest. 111:381-387. doi:10.1172/JCI200316774.

37. Wei, S., Charmley, P., Robinson, M.A., and Concannon, P. 1994. The extent of the human germline $\mathrm{T}$-cell receptor $\mathrm{V}$ beta gene segment repertoire. Immunogenetics. 40:27-36.

38. Pannetier, C., Even, J., and Kourilsky, P. 1995. T-cell repertoire diversity and clonal expansions in normal and clinical samples. Immunol. Today. 16:176-181.

39. Pannetier, C., Levraud, J.P., Lim, A., Even, J., and Kourilsky, P. 1998. The immunoscope approach for the analysis of $T$ cell repertoires. In The antigen $T$ cell receptor: selected protocols and applications. J.R. Oksenberg, editor. Chapman and Hall. London, United Kingdom. 287-325.

40. van Dongen, J.J., et al. 2003. Design and standardization of PCR primers and protocols for detection of clonal immunoglobulin and $\mathrm{T}$-cell receptor gene recombinations in suspect lymphoproliferations: report of the BIOMED-2 Concerted Action BMH4CT98-3936. Lenkemia. 17:2257-2317.

41. Langerak, A.W., Szczepanski, T., van der Burg, M., Wolvers-Tettero, I.L., and van Dongen, J.J. 1997. Heteroduplex PCR analysis of rearranged T cell receptor genes for clonality assessment in suspect T cell proliferations. Lenkemia. 11:2192-2199.

42. Fisch, P., et al. 1990. T cell clones and natural killer cell clones mediate distinct patterns of non-major histocompatibility complex-restricted cytolysis. J. Exp. Med. 171:1567-1579.

43. Fisch, P., et al. 1997. Control of B cell lymphoma recognition via natural killer inhibitory receptors implies a role for human Vgamma9/Vdelta2 T cells in tumor immunity. Eur. J. Immunol. 27:3368-3379.

44. Linke, B., et al. 1997. Automated high resolution PCR fragment analysis for identification of clonally rearranged immunoglobulin heavy chain genes. Lenkemia. 11:1055-1062.

45. Schwarz, K., et al. 1996. RAG mutations in human B cell-negative SCID. Science. 274:97-99. 